\title{
Experimental Research on the Adhesion Characteristics of Clay to Structures with Different Materials
}

\author{
Tao Qiu $\mathbb{D}^{1}$ and Yonggang Zhang $\mathbb{D}^{2}$ \\ ${ }^{1}$ School of Civil Engineering, Nanjing Forestry University, Nanjing, Jiangsu Province 210037, China \\ ${ }^{2}$ Key Laboratory of Geotechnical and Underground Engineering of Ministry of Education and Department of \\ Geotechnical Engineering, Tongji University, Shanghai 200092, China
}

Correspondence should be addressed to Yonggang Zhang; demonzhangyg@tongii.edu.cn

Received 1 June 2021; Revised 12 July 2021; Accepted 24 July 2021; Published 4 August 2021

Academic Editor: José Luis Pastor

Copyright (c) 2021 Tao Qiu and Yonggang Zhang. This is an open access article distributed under the Creative Commons Attribution License, which permits unrestricted use, distribution, and reproduction in any medium, provided the original work is properly cited.

\begin{abstract}
When the shield machine passes through the clay layer, the clay debris cut by the cutter head usually adheres to the surface of the cutter head and is easy to form mud cakes after extrusion, which affects the safety and efficiency of construction. For the structure made of different materials, due to the different surface properties, the adhesion characteristics of clay are also different. So, selecting proper materials for the soil contacting parts in the shield machine can effectively reduce the adhesion between the structure and soil, decrease the clay adhering to the surface of the shield cutter, and reduce the possibility of further productions of mud cake. Therefore, studying the adhesion properties of clay to different materials and understanding the adhesion rule of clay to soil contacting structures are of guiding significance when selecting the materials of soil contacting parts. In this paper, the adhesion properties of cohesive soil to commonly used construction materials were studied by a self-made adhesion test device, including steel, iron, copper, aluminum, and engineering plastics (polyamide). According to the findings, the separation process of adhesion between soil and the structure by an external force can be divided into four stages, which are the adhesive elastic development stage, adhesive plastic development stage, failure stage, and detachment stage. The adhesion forces and the amount of soil adhered to the structures made of the selected materials are found to vary from each other. The adhesion forces ranked from high to low are, respectively, found on the iron, plastic, aluminum, steel, and copper surfaces. The material with the most amount of adherent soil is aluminum, followed by iron, steel, copper, and plastic.
\end{abstract}

\section{Introduction}

The shield construction method is widely used in tunnel construction because of its high efficiency, environmental friendliness, and little impact on people's everyday traffic life [1-3]. However, when the shield machine passes through the clay stratum, the clay debris cut off usually adheres to the surface of the shield cutter. After the compaction of the shield cutter, the clay debris is very likely to form solid or semisolid blocks (i.e., mud cakes) attached to the surface of the cutter. When the mud cake occurs, the tools on the cutter can be stuck by the consolidated clay, resulting in reduced tool penetration when cutting the stratum [4-7]. In severe cases, the increase of rotation torque of the cutter head can result in a significant fluctuation of shield parameters, blocking of mud pipes, and so on, affecting the safety and efficiency of construction [8-11]. Therefore, the soil adhesion on the cutter surface is one of the important reasons for the occurrence of the mud cake [12-16].

Structures made of different materials have different surface properties, causing various adhesion characteristics of the clay to the structures $[17,18]$. Adopting appropriate materials can reduce the adhesion force on the interface between the structure and soil effectively and lower the adhesion degree of clay. Hence, using a suitable cutter material can reduce the adhesion of clay debris to the surface of the cutter and reduce further productions of mud cakes. Therefore, it is instructive to study the adhesion characteristics of clay to the structures of various materials and understand the adhesion rule of clay to the soil contacting part. 


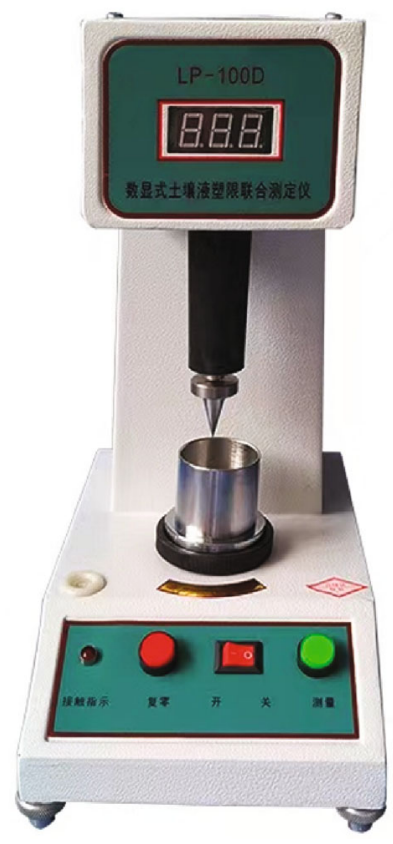

(a) Liquid-plastic limit tester

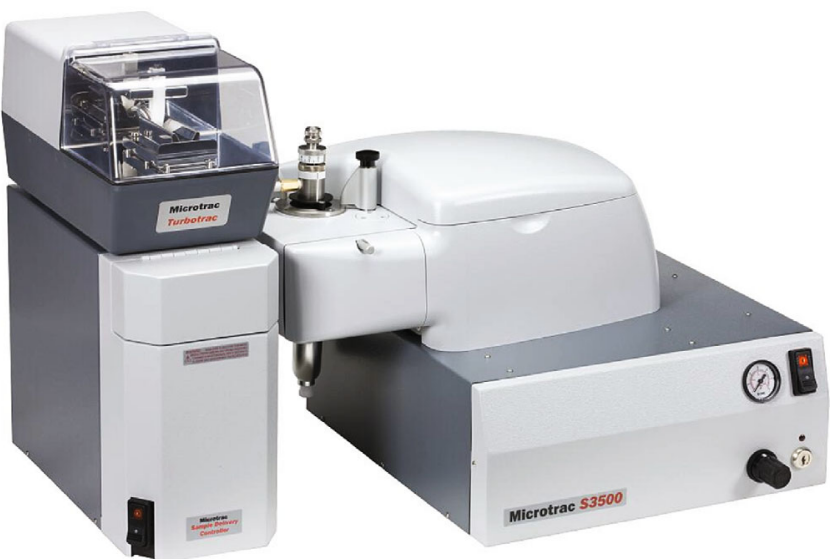

(b) Laser particle size analyzer

FIGURE 1: Soil property testing equipment.

TABle 1: Physical parameters of used clay soil sample [23].

\begin{tabular}{lccccc}
\hline Plastic limit (\%) & Liquid limit (\%) & Nonuniform coefficient & Dominant diameter $(\mu \mathrm{m})$ & Silt particle content $(\%)$ & Clay particle content $(\%)$ \\
\hline 21.26 & 37.5 & 7.52 & 47.87 & 66.92 & 7.38 \\
\hline
\end{tabular}

With the clay soil samples taken from the D1N-TA04 section of the North Extension Project of Nanjing Metro Line 1 , we designed and manufactured a set of devices for testing the interface adhesion force. By applying a normal force to the interface, the designed device can separate the adhesion and determine the minimum force required for the separation. Meanwhile, we made a series of soil contacting parts using steel, iron, copper, aluminum, and engineering plastics (polyamide), which are all commonly used in construction machinery as structural interface material. The soil used for testing the parts had a moisture content of $23 \%$. In the tests, the change of tensile forces during the separation process and the adhesion of soil on the structure surface after interface separation were recorded, which was later used to analyze the adhesion characteristics of clay to structures made of different materials. This study is aimed at providing some reference for understanding the influence of structural materials on soil adhesion, guiding the reasonable use of soil contact structural materials, and reducing the adhesion of soil on the surface of machines and tools during construction.

\section{Materials and Methods}

2.1. Properties of Soil Samples. In order to solve a series of problems met in the shield tunnelling process of the Nanjing subway tunnel, the clay soil samples taken from the D1NTA04 section of the North Extension Project of Nanjing
Metro Line 1 were selected and studied in this paper. The liquid plastic limit and particle size of the soil sample were tested by the soil property testing device shown in Figure 1. The obtained physical properties of the soil are listed in Table 1, and the particle aggregation curve is presented in Figure 2. According to the Code for Investigation of Geotechnical Engineering (GB50021-2018) standard, the tested soil samples were classified as silty clay, and the size distribution of the soil particles is relatively uniform [19-22].

2.2. Preparation of Soil Samples. As shown in Figure 3, in order to prepare the soil samples required for the tests, the soil was placed in an oven with a preset temperature of $105^{\circ} \mathrm{C}$, and the heating time was more than 24 hours. Then, the soil was crushed in a crusher and sifted through a sieve with a pore diameter of $0.5 \mathrm{~mm}$. Following that, pure water weighing $23 \%$ of the soil was added to the collected soil. The wellstirred soil was then layered into a plastic box, and the surface of the soil was levelled with a scraper, wrapped with plastic film, and placed for more than 24 hours to make the soil samples. Before the tests, we measured the moisture content of the soil samples, and those whose error between the measured moisture content and the designed moisture content is less than $0.5 \%$ were used in the subsequent tests.

2.3. Experimental Apparatus. To study the adhesion characteristics of the cohesive soil to structures made of different materials, steel, iron, copper, aluminum, and engineering 


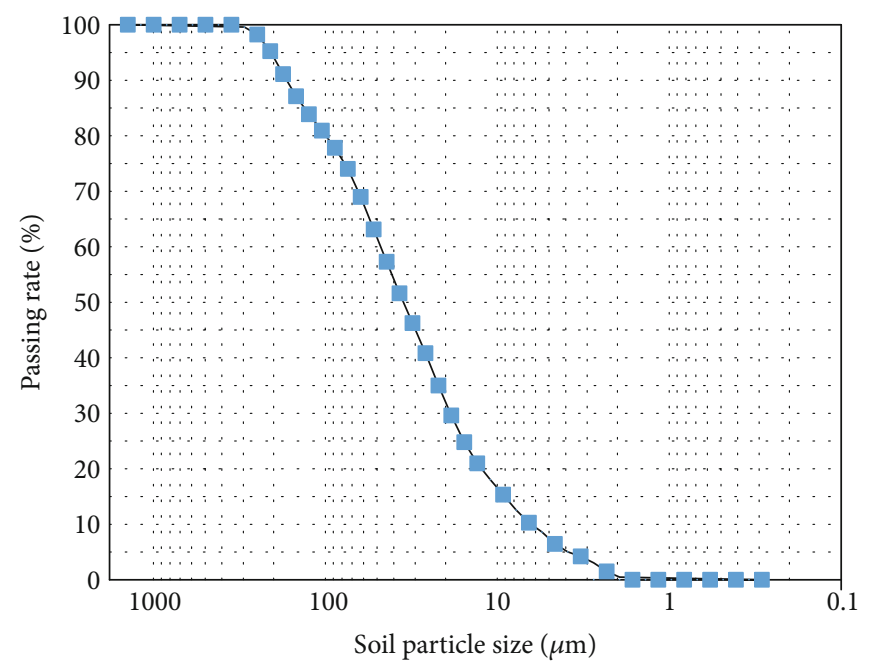

FIgURE 2: Soil particle aggregation curve [23].

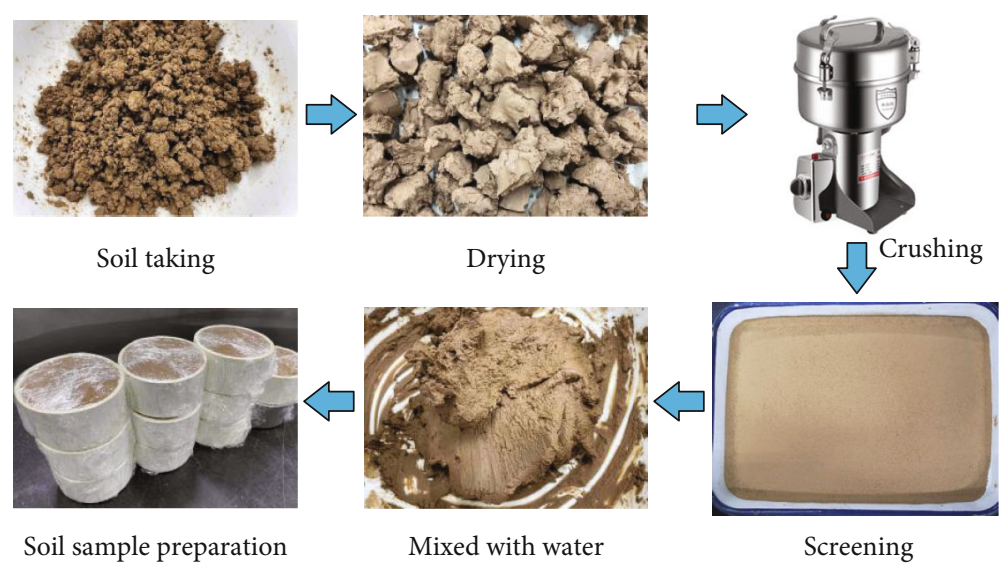

FIGURE 3: Preparation of test soil samples.

plastics (polyamide) were selected and used in this experiment to make the test specimens. In order to reduce the influence of lateral friction on the test results and make the soil fully contact with the structure surface, we made 5 test cones as the test specimens referring to other investigators' work $[24,25]$ (see Figure 4). The top angle of the test cones is $54.4^{\circ}$, and the generatrix of the lower cone is $35 \mathrm{~mm}$. Before the tests, the specimens were polished until the processing trace was not visible to the naked eye; then, the surfaces of the specimens can be regarded as meeting the manufacturing requirements [26-28]. Detailed parameters of the test cone are shown in Table 2.

Based on relevant testing methods provided by other investigators, the adhesion force test device as shown in Figure 5 was designed and fabricated, which was used as the traction device to separate the contact and record the tension in the separation process. In the device, the stepper motor drives the electronic tension meter to produce vertical displacement through the screw sliding table, and the motor is controlled by the pulse generator and the driver. The electronic tension meter is connected with the extension rod and the test cone to produce a vertical displace- ment, measure the tension in the testing process, and output it to the computer.

2.4. Experimental Design. The cones made of steel, iron, copper, aluminum, and engineering plastics were first plugged into the soil mentioned above and pulled up at a rate of $5 \mathrm{~mm} / \mathrm{min}$, slowly applying the normal force to separate the soil-structure interface. The tensile force change process and the amount of soil adhesion on the structural surfaces after interface separation were recorded. The test method follows the steps given below.

(1) Choose one of the test cones and connect it to the electronic tension meter of the electric traction test device by an extension rod

(2) Place the prepared soil sample just below the test cone so that the center of the soil sample is aligned with the tip of the test cone

(3) Connect the power of the electric traction test device, connect the computer to the electronic tension meter 


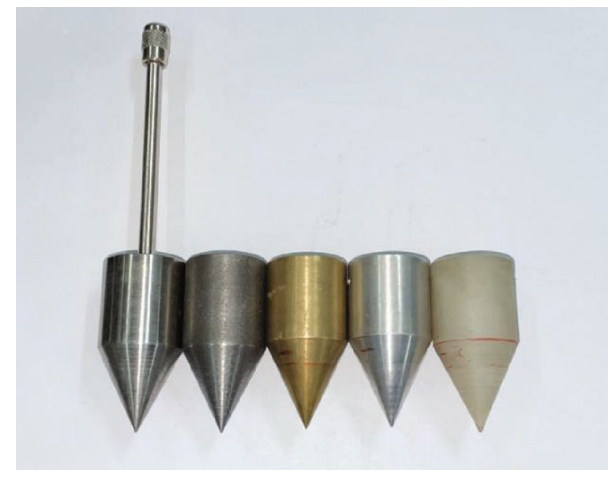

(a) Physical diagram

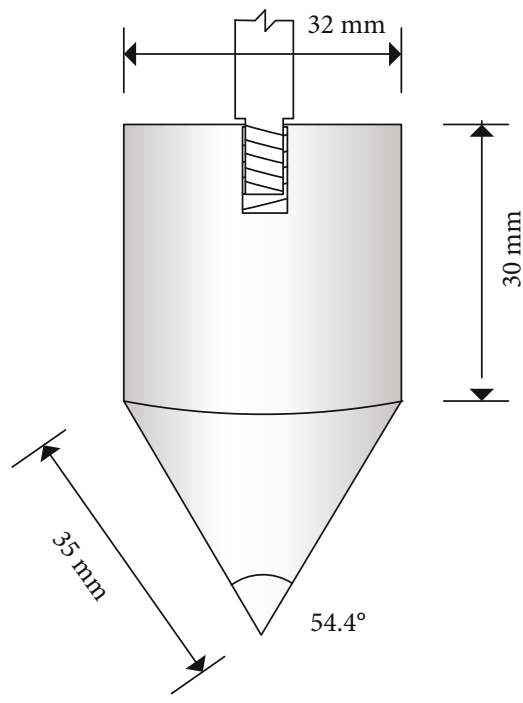

(b) Schematic diagram

Figure 4: Test cone.

TABLe 2: Parameter of test cone.

\begin{tabular}{|c|c|c|c|c|c|}
\hline Test cone & Steel & Iron & Copper & Aluminum & Plastics \\
\hline Structural materials & 304 steel & HT200 gray cast iron & H62 brass & 7075 aluminum & Polyamide \\
\hline Roughness & & & $R_{\mathrm{a}} 0.2-0.8 \mu \mathrm{m}$ & & \\
\hline Generatrix & & & $35 \mathrm{~mm}$ & & \\
\hline Top angle & & & $54.4^{\circ}$ & & \\
\hline Cylinder diameter & & & $32 \mathrm{~mm}$ & & \\
\hline Cylinder height & & & $30 \mathrm{~mm}$ & & \\
\hline Cone area & & & $1.6485 \cdot 10^{-3} \mathrm{~m}^{2}$ & & \\
\hline
\end{tabular}

through a data acquisition line, and check the operation of the device and data acquisition

(4) Move the test cone down slowly so that the tip of the cone touches the top surface of the test sample

(5) Set the electronic tension meter to zero

(6) Open the electric traction test device and make the traction test device slowly drive the test cone down at a constant speed and make the lower part of the test cone stab into the soil vertically

(7) Open the data acquisition software and start collecting the tension data collected by the electronic tension meter

(8) Reverse the direction of the electric traction test device, adjust the traction speed at $5 \mathrm{~mm} / \mathrm{min}$, then lift the test cone slowly at a constant speed until the surface of the test cone is completely separated from the soil, and finish the data sampling and save

(9) Select another cone made of other materials and repeat the procedure above

No less than 3 repetitions should be performed for each material test cone.

\section{Results}

3.1. Soil Adhesion to the Structure Surfaces of Different Materials. At the beginning of the test, the soil tended to flow around immediately after contacting the tip of the test cone. With the compression process of the test cone, the soil around the cone tip began to extend to the upper of the cone surface, and the soil formed a contact surface with the specimen surface (see Figure 6). The redistribution of soil particles and soil water made the contact area gradually increase, and water rings started to appear on the contact surface until the water film formed the adhesive interface. When applying an external force to the test cone, the adhesion interface was broken along the weakest antistripping plane. When the surface occurs inside the soil, the broken soil adhered to the surface of the test cone and eventually became the adhered soil [15].

It can be seen from Figure 7 that cohesive soil has different adhesion characteristics on structures made of different materials. As shown in Figure 8, under the condition of $23 \%$ soil moisture content and $26^{\circ} \mathrm{C}$ interface temperature, among the five structure materials, after the separation of the soil-structure interface, the amount of adhered soils at the iron and aluminum surfaces are significantly more than those of the other three materials. The adhered soil is 


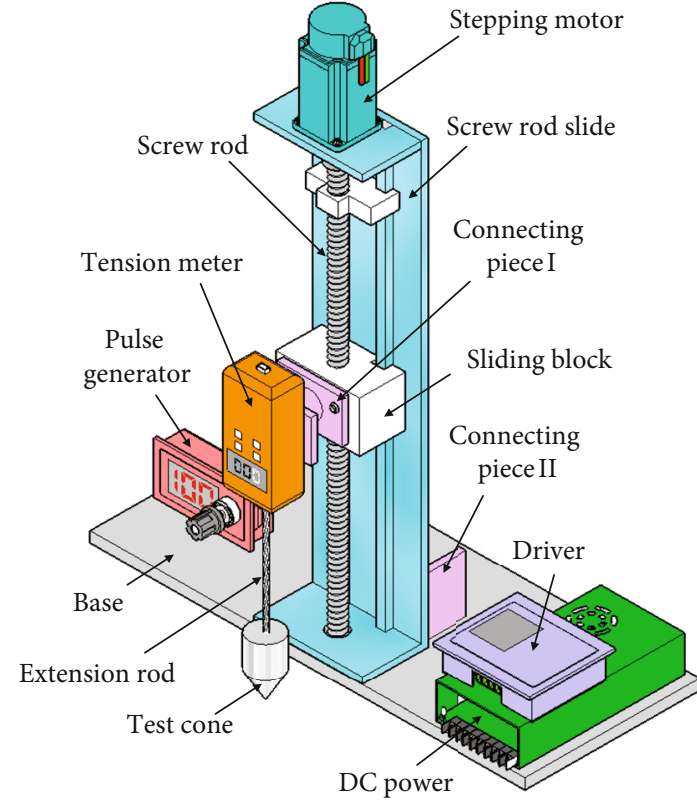

(a) Schematic diagram

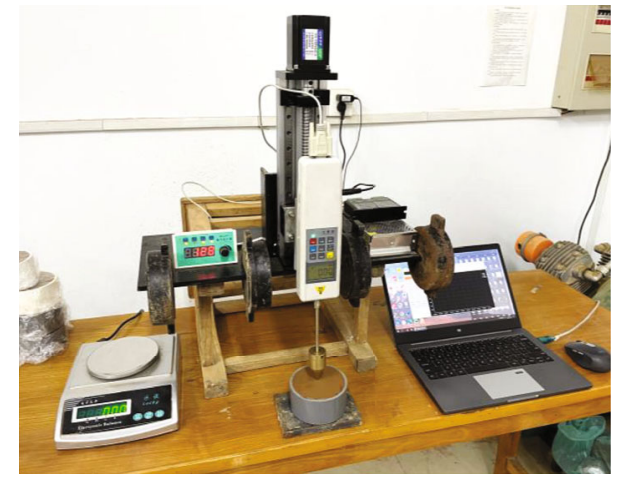

(b) Physical diagram

Figure 5: Adhesion force test device.

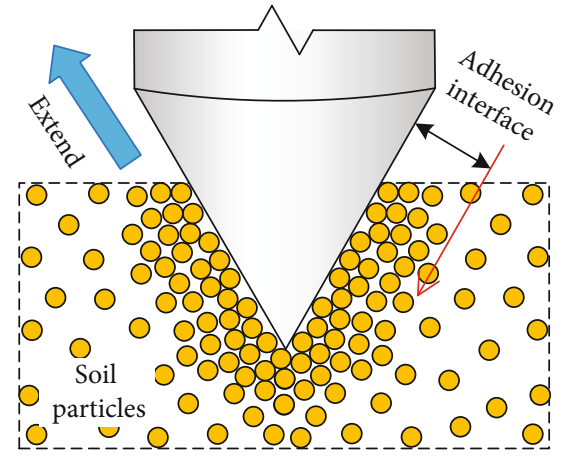

FIgure 6: The soil mass forms contact surface with the specimen surface.

distributed on the whole surface of the cone, and a large proportion is in the middle of the cone, which appears as clumps. As for steel, copper, and plastic structures, the surface adhesions were slight, and tiny soil particles remained on the cone tips. Among the structures of five materials, the aluminum structure surface attracted the most soil, with a density of $20.0 \mathrm{mg} / \mathrm{cm}^{2}$. It was followed by the iron structure, with a density of $10.5 \mathrm{mg} / \mathrm{cm}^{2}$, which was about $47 \%$ less. The densities for the steel, copper, and plastic structures are similar and relatively low, which is about $0.8 \mathrm{mg} / \mathrm{cm}^{2}$ and only $4 \%$ of the aluminum structure and $8 \%$ of the iron structure.

In the work of Deng, the investigator replaced the lower box of the direct shear apparatus with plates of various materials to make a tangential adhesion testing device, which was used to study the tangential adhesion relationship between soil and the structure of various materials [29]. Similarly, he found that soil adhesion test results were material dependent, which was reflected in the adhesion interface's failure modes when the tangential failure occurred. In tangential interface

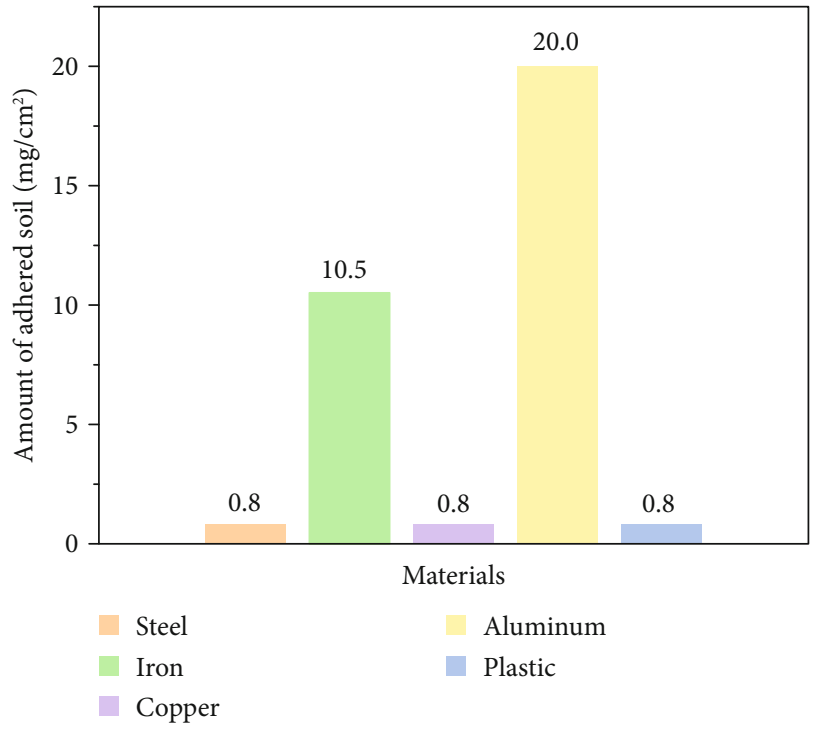

Figure 7: The conditions of soil adhering to structural interface material surface.

adhesion, the amount of soil that adhered to the iron surface was the most after interface failure, followed by copper and aluminum. Considering that his results were not completely consistent with the findings in this work, the failure mode of the adhesion interface may presumably affect the adhesion of soil with structures of different materials.

After the tests, the trace of uniform and complete contact with the soil can be clearly observed on the surface of each cone. This indicates that the test device and the test cone can be well used to test the adhesion characteristics between cohesive soil and structure interface and can well show the adhesion characteristics between soil and structure interface. 

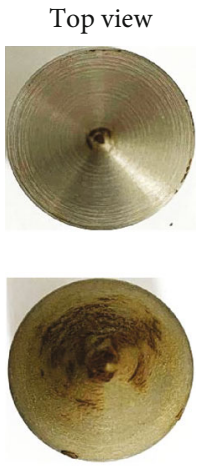

(a)
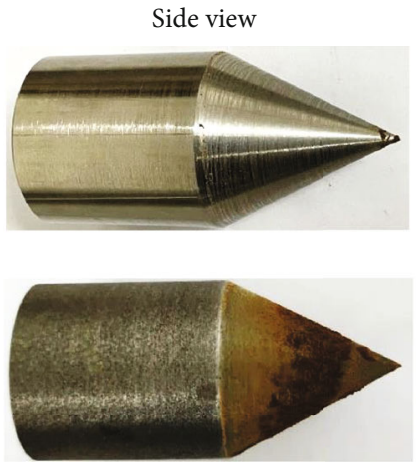

(b)
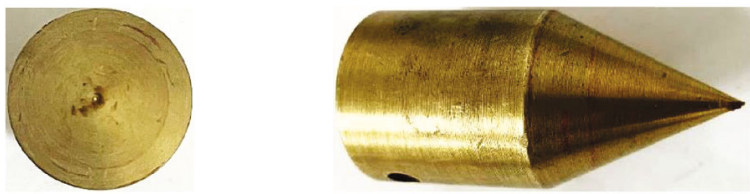

(c)
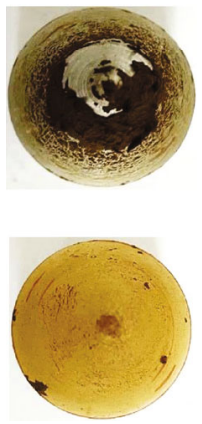

(d)
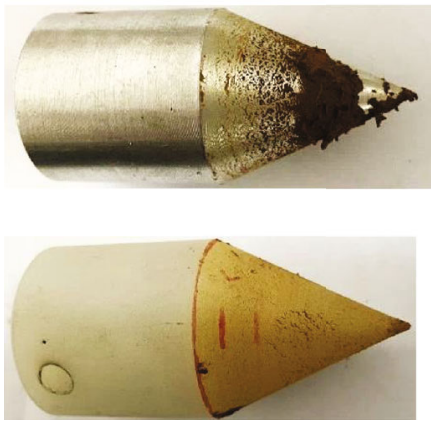

(e)

Figure 8: The amount of soil attached to the surface of different material structures.

3.2. The Characteristics of Soil Adhesion Force on Structures of Different Materials. The soil was bonded to the structure surface when they were closely contacted. By applying a normal force on the contact interface, the connection can be separated. The required minimum force on the unit area of the contact interface is called the adhesion force [30], which is expressed by $F$ :

$$
F=\frac{P}{A}
$$

where $F$ is the adhesion force and $A$ is the contact area between the soil and structure surface.

Figure 9 shows the adhesion force vs. displacement curves on interfaces of various materials. For each material, three parallel test groups have been conducted. It can be seen from the figure that the three groups of curves of each material test are consistent. The maximum adhesion difference was less than $5 \%$, and the data test was stable and effective. It can be seen that the adhesive forces of clay to structures of different materials are different. Among the five materials, plastic and iron cause the most significant adhesion forces, with average values of $14.61 \mathrm{kPa}$ and $14.85 \mathrm{kPa}$, respectively. They are followed by aluminum, steel, and copper in order, and the corresponding adhesion forces are $11.08 \mathrm{kPa}$, $6.74 \mathrm{kPa}$, and $5.56 \mathrm{kPa}$, respectively.

For the structures of steel, copper, and plastic, which have little soil on the surface of the cone after separation, only a small further displacement $(<1 \mathrm{~mm})$ is needed to make the soil adhesion drop rapidly and reach the abovementioned failure stage. For the materials with more soil on the surface, such as iron and copper, increasing the vertical displacement of the test cone after the adhesion reaches the maximum value can only make the adhesion slowly decrease for the first $2 \mathrm{~mm}$. After that, increasing the vertical displacement makes the interface of soil and structure rapidly separate, and the adhesion rapidly decreases.

The characteristics of adhesion force during the interface separation between soil and each material structure were analyzed (see Figure 10). It can be seen from the figure that the curves can be divided into four stages: elastic development, adhesive plastic development, destroy, and detachment.

(1) Elastic Development Stage. At the beginning (point a), the surface of the test cone is in complete contact with the test soil, and there is a bonding pressure between them. From this point, the applied force gradually weakens the bonding pressure and causes the rebound deformation to occur. When the tension continues, the bonding pressure disappears completely, and a drag force is generated on the contact surface to overcome the pull-up force. Because the soil is a natural elastic-plastic material, elastic deformation occurs in a certain range of soil interface, and the deformation reaches the maximum with the increase of tensile force (point b). The results show that there is a linear relationship between the tensile force and the pull-up displacement at this stage, and the slope of the stage is basically similar for all the structures. Therefore, the soil deformation at this stage can be considered elastic deformation.

(2) Adhesive Plastic Development Stage. After the elastic development is complete (point b), the soil near the interface begins to deform by further application of pull-up force. At this time, the development of adhesive force slows down, showing a trend of plastic development until it reaches the maximum (point c). Then, the adhesive interface begins to separate along the weak surface, and with the increase of displacement, the tensile force gradually decreases until the tear develops to the maximum (point $\mathrm{d}$ ). At this stage, the tensile force decreases with the increase of displacement, and the adhesive force develops elastically.

(3) Failure Stage. At this stage, the expansion of the weak surface completes at the $\mathrm{d}$ point, and the test cone and soil begin to separate. When point e is reached, the cone surface is completely separated from the test soil, and the tension between the soil and the structure almost disappears. It can be seen from the figure that the displacement at this stage is very small, so it belongs to brittle fracture separation. 

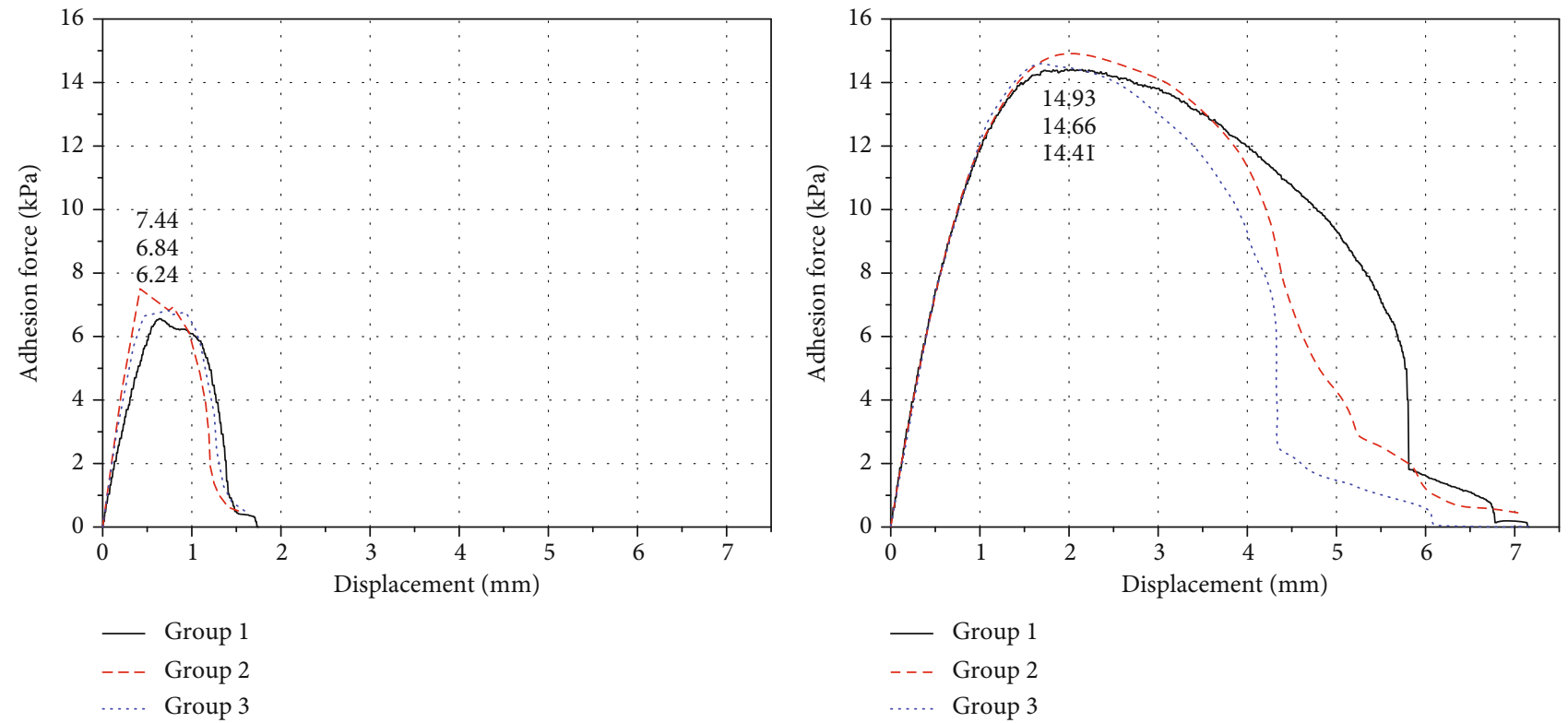

(a) Steel
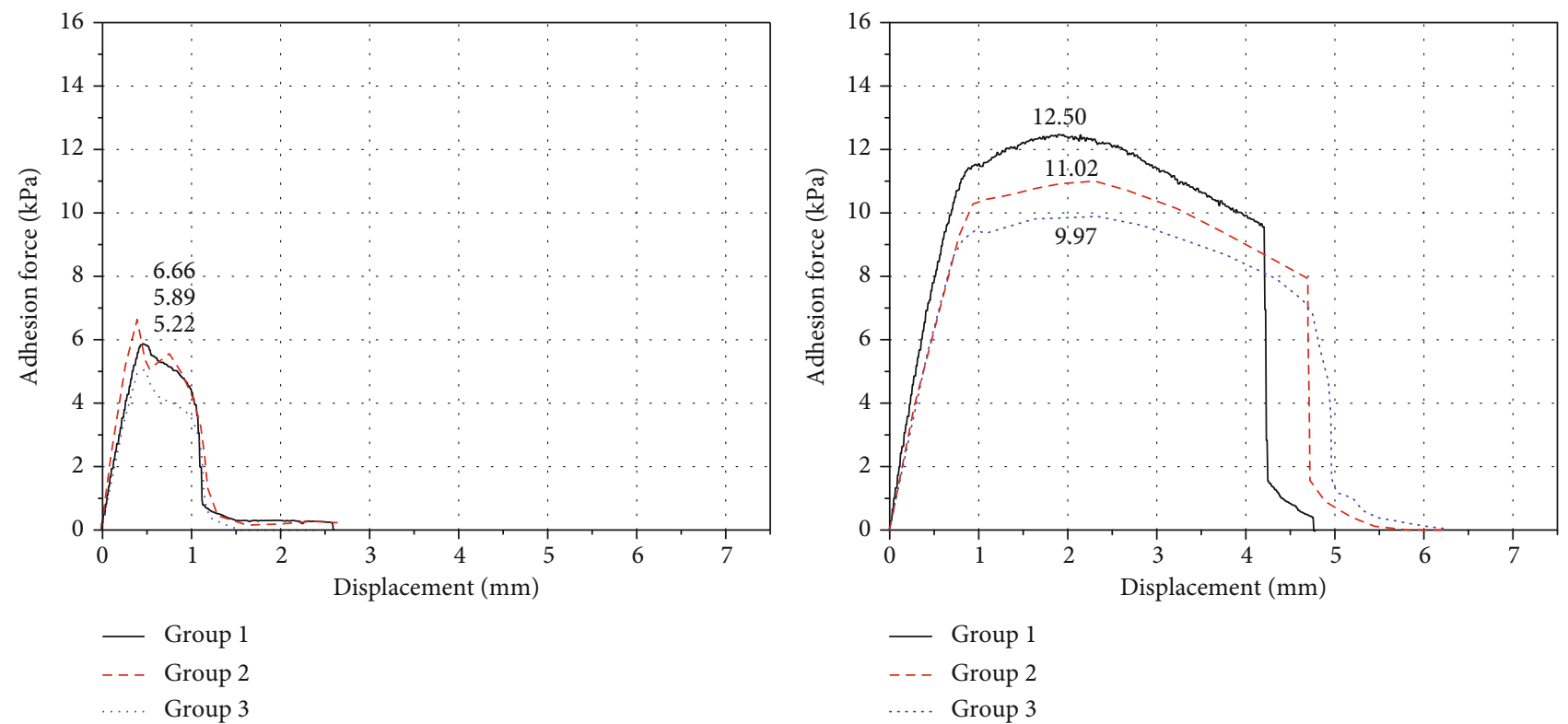

(c) Copper

(d) Aluminum

Figure 9: Continued. 


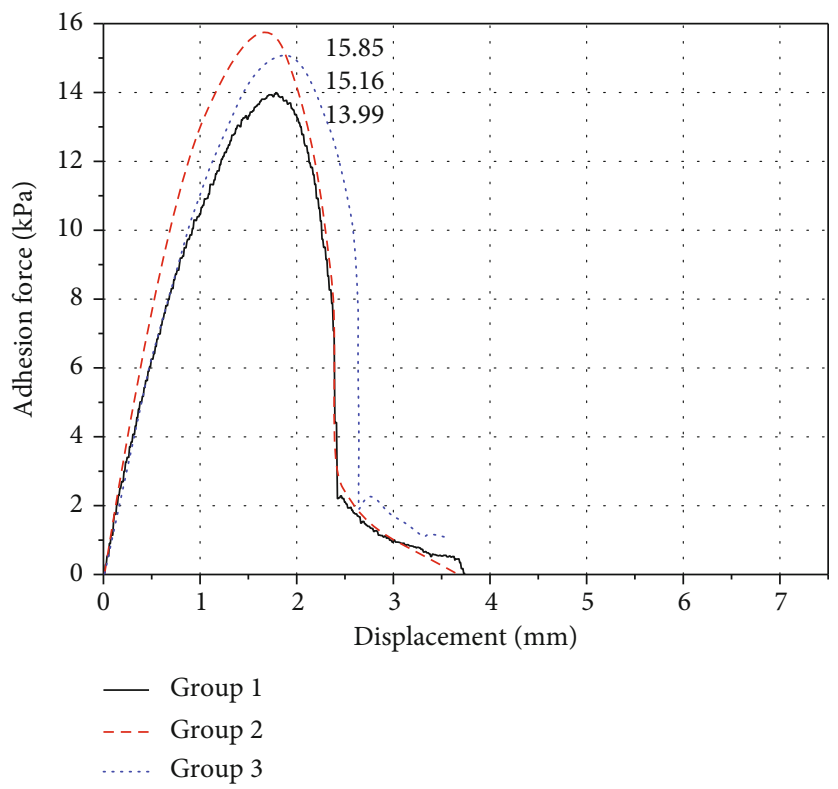

(e) Plastic

Figure 9: Interfacial adhesion force-displacement curve of each material.

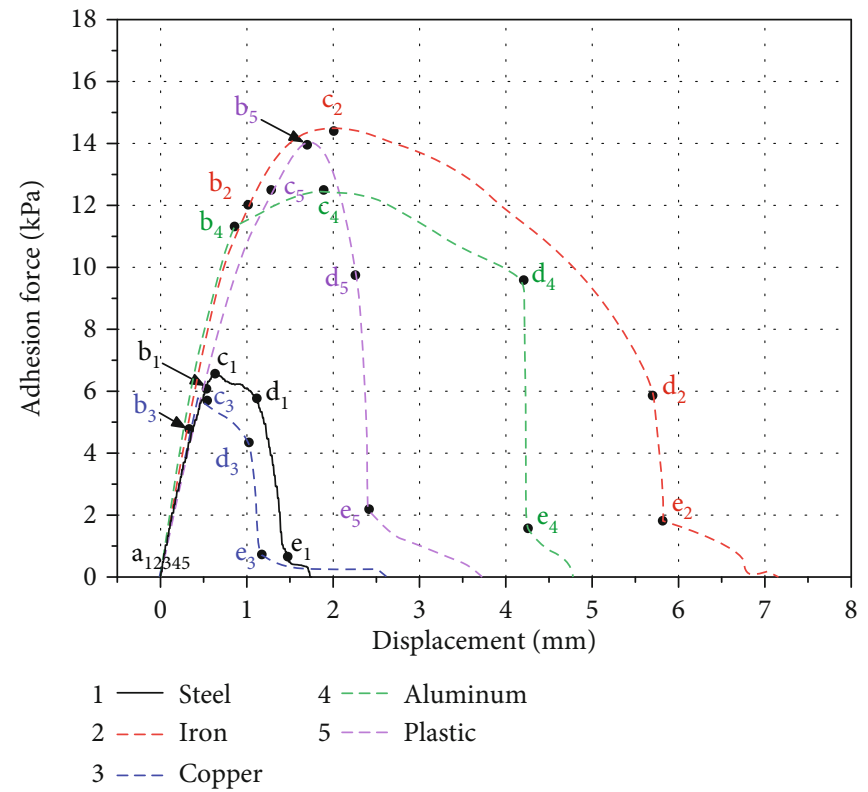

FIgURE 10: The tensile force vs. pull-up displacement.

(4) Detachment Stage. After the d point, the tension between soil and structure almost disappears completely. At this time, only a small number of cohesive soil attached to the surface of the structure contact with the soil body below. With the increase of displacement, these contacts are completely separated, and the tensile force is completely disappeared.

\section{Discussion}

4.1. Formation of Soil Adhesion. Molecules on a material surface are attracted to the interior of the material. These mole- cules need to consume energy to resist this attraction. Therefore, molecules on the surface of a substance have more energy than internal molecules. The excess energy is called surface free enthalpy, also known as surface free energy. The free enthalpy per unit surface area can be expressed by

$$
G=\sigma A
$$

The surface free enthalpy $G$ is the product of surface tension $\sigma$ and surface area $A$. The high energy material is obviously in a very unstable state, so the free enthalpy of cohesive soil tends to decrease automatically. When the 


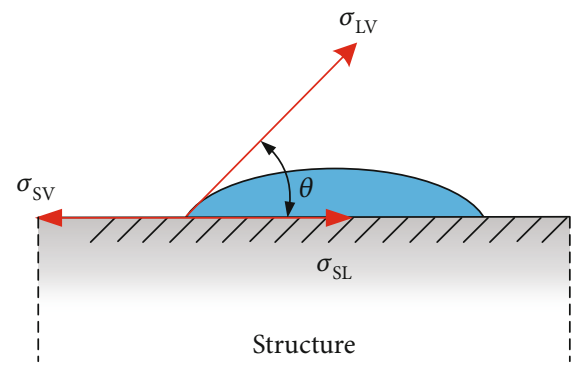

(a) Hydrophilic

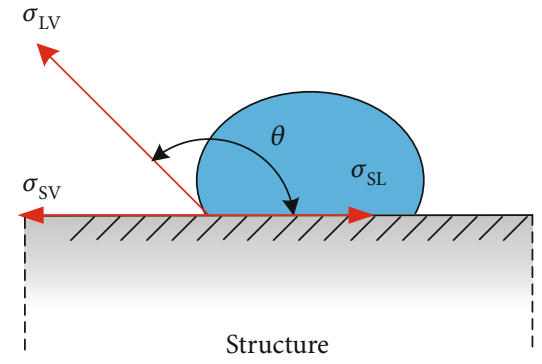

(b) Hydrophobic

FIGURE 11: Wettability of liquid to solid surface.

cohesive soil is in contact with water, the free energy of the soil interface is smaller than the sum of the surface free energy of the original soil and water, which leads to the decrease of the surface energy of the cohesive soil. This phenomenon is called the wetting phenomenon. When the soil has certain water content, the soil particles are wetted by the soil water and form a water film on the surface of the soil particles. When the water film thickness reaches a certain value, the soil particles are wetted with the external structure surface, which makes the soil particle water external structure stick together, resulting in adhesion.

4.2. Soil Adhesions of Different Materials. Different structural materials have different water wetting abilities, i.e., the ability of water molecules to spread over a solid surface, which can be expressed by the size of the contact angle [31, 32]. As shown in Figure 11, the corresponding interfacial tensions on the solid-liquid, liquid-gas, and gas-solid interfaces are $\sigma_{\mathrm{SL}}, \sigma_{\mathrm{LV}}$, and $\sigma_{\mathrm{SV}}$, respectively. When each interfacial tension reaches balance, the resultant force is zero, and the angle satisfies

$$
\begin{aligned}
\sigma_{\mathrm{SV}} & =\sigma_{\mathrm{SL}}+\sigma_{\mathrm{LV}} \cos \theta \\
\operatorname{orcos} \theta & =\frac{\left(\sigma_{\mathrm{SV}}-\sigma_{\mathrm{SL}}\right)}{\sigma_{\mathrm{LV}}},
\end{aligned}
$$

where $\theta$ is the contact angle, also known as wetting angle, which can be used to represent the wetting ability of liquid on solid.

According to Figure 11, when $\sigma_{\mathrm{SV}}>\sigma_{\mathrm{SL}}, \cos \theta<0^{\circ}, 90^{\circ}$ $<\theta<180^{\circ}$, the water has a weak wetting ability, and it increases with the decrease of $\theta$. When $\sigma_{\mathrm{SV}}<\sigma_{\mathrm{SL}}, \cos \theta>0^{\circ}$, $0<\theta<90^{\circ}$, the water has the largest wetting ability, and it decreases with the increase of $\theta$.

Therefore, the material with strong water adsorption capacity has greater adhesion to soil clay. If the surface of structural material is hydrophilic, the adhesion between it and cohesive soil is strong and vice versa. The adhesion of soil to the structure surface is determined by the surface free energy of soil and material structure.

4.3. Adhesion of Soil to the Surface of Structure. From the analysis above, it can be seen that when the soil and the solid material surface contact under a certain pressure, the original soil surface and the structural surface become an adhesion interface, and the interfacial tension decreases. If the interface needs to be separated, extra energy is required for the adhesion system, and applying a normal force is the way [15].

When soil adhesion occurs, it involves the dynamic change of the soil layer at a certain depth below the interface, resulting in the occurrence of the weakest plane in the interface layer. At this time, if the external adhesive force of soil on the structure surface is greater than cohesive force, the adhesion phenomenon occurs. These soils are adhered to or move with the surface of the structure, causing the attached soil. Moreover, due to the adhesion ability differences of different materials, the amount of soil adhesion on the surfaces is different after the interface separation.

\section{Conclusions}

Based on the experimental results and phenomenon discussion of soil adhesion to different material structures mentioned above, the main findings are as follows.

(1) Soil, water, and structure act together to form an interface adhesion system. For the structure surfaces of different materials, the wetting abilities of water are different, causing different adhesion forces on the surfaces. From high to low, adhesion forces are observed on the iron, plastic, aluminum, steel, and copper surfaces

(2) Applying normal force on the interface can separate the adhesion, and the process can be divided into four stages, which are elastic development, plastic, failure, and detachment. For the materials with more adhered soils after interface separation, the adhesive force plastic development stage is relatively long. For the materials with less surface soil, the stage of plasticity development is very short. When the adhesion reaches the failure stage, detachment occurs rapidly, resulting in brittle failure separation

(3) The soil is pulled off along the weakest antistripping plane and moves on the surface of the cone. After that, the soil usually adheres to the structure surface and becomes adhered soil. Due to the adhesion capacity difference of soil to different material surfaces, the amount of adhered soil is different after the interface separation. Among the specimens, the 
aluminum structure surface has the most adhered soil, and it is followed by iron, and the adhesion on the steel, copper, and plastic surfaces is very insignificant

\section{Data Availability}

The data are generated from experiments and can be available from the corresponding author upon request.

\section{Conflicts of Interest}

The authors declare that there are no conflicts of interest regarding the publication of this paper.

\section{Authors' Contributions}

Tao Qiu carried out the experiments, analyzed the results, conducted the theoretical explanations, and wrote the manuscript. Yonggang Zhang provided constructive suggestions, performed significant review and editing of the technical paper, and provided rigor and fluency in the language of the academic paper.

\section{Acknowledgments}

The authors would like to express appreciation to the Faculty of Civil Engineering, Nanjing Forestry University, for providing the laboratory.

\section{References}

[1] F. Ye, N. Qin, X. Gao, X. Y. Quan, X. Z. Qin, and B. Dai, "Shield equipment optimization and construction control technology in water- rich and sandy cobble stratum: a case study of the first yellow river metro tunnel undercrossing," Advances in Civil Engineering, vol. 2019, Article ID 8358013, 12 pages, 2019.

[2] J. Zhang, L. Ye, C. Yan, B. Yan, P. Wei, and J. Feng, "Study on construction influence of shield tunnel of urban rail transit on large-section mining tunnel," Advances in Civil Engineering, vol. 2020, Article ID 6836492, 20 pages, 2020.

[3] W. Gang, "Prediction of ground deformation induced by shield tunneling construction," Chinese Journal of Rock Mechanics and Engineering, vol. 28, no. 2, pp. 418-424, 2009.

[4] S. Zhao, S. Li, Z. Wan, and M. Wang, "Dispersant for reducing mud cakes of slurry shield tunnel boring machine in sticky ground," Advances in Materials Science and Engineering, vol. 2021, Article ID 5524489, 10 pages, 2021.

[5] S. Song, R. Tian, L. Li, J. Hu, C. Shen, and S. Peng, "Adaptability study of EPB shield machine in clay stratum in Xuzhou," Geotechnical and Geological Engineering, vol. 37, no. 4, pp. 2335-2341, 2019.

[6] Z. Wan, S. Li, C. Yuan et al., "Soil conditioning for EPB shield tunneling in silty clay and weathered mudstone," International Journal of Geomechanics, vol. 21, no. 9, article 06021020, 2021.

[7] S. Islam, D. J. Williams, M. Llano-Serna, and C. Zhang, "Settling, consolidation and shear strength behaviour of coal tailings slurry," International Journal of Mining Science and Technology, vol. 30, no. 6, pp. 849-857, 2020.
[8] F. Hollmann and M. Thewes, "Assessment method for clay clogging and disintegration of fines in mechanised tunnelling," Tunnelling and Underground Space Technology, vol. 37, pp. 96-106, 2013.

[9] M. Feinendegen, M. Ziegler, G. Spagnoli, T. Fernández-Steeger, and H. Stanjek, "A new laboratory test to evaluate the problem of clogging in mechanical tunnel driving with EPBshields," in ISRM International Symposium-EUROCK 2010, Ed., OnePetro, pp. 429-432, 2010.

[10] M. Feinendegen, M. Ziegler, G. Spagnoli, and T. FernándezSteeger, "Evaluation of the clogging potential in mechanical tunnel driving with EPB-shields," in Proceedings of the 15th European Conference on Soil Mechanics and Geotechnical Engineering Ed., IOS Press, pp. 1633-1638, 2011.

[11] F. S. Khan and S. Azam, "A framework for coupled consolidation-desiccation behaviour of clay slurries," International Journal of Mining Science and Technology, vol. 28, no. 2, pp. 275-280, 2018.

[12] G. Spagnoli, M. Feinendegen, and T. Fernandez-Steeger, "Influence of salt solutions on the undrained shear strength and the clogging of smectite-quartz mixtures," Environmental \& Engineering Geoscience, vol. 17, no. 3, pp. 293-305, 2011.

[13] A. Khabbazi, M. Ghafoori, S. Tarigh azali, and A. Cheshomi, "Experimental and laboratory assessment of clogging potential based on adhesion," Bulletin of Engineering Geology and the Environment, vol. 78, no. 1, pp. 605-616, 2019.

[14] I. Sass and U. Burbaum, "A method for assessing adhesion of clays to tunneling machines," Bulletin of Engineering Geology and the Environment, vol. 68, no. 1, pp. 27-34, 2009.

[15] M. A. Khan, R. Qaisrani, and J.-Q. Li, "The techniques of reducing adhesion and scouring soil by bionic-review of literature," Advances in Natural Science, vol. 3, no. 2, pp. 41-50, 2010.

[16] C. Zhu, G. Li, Y. Xing, and X. Gui, "Adhesion forces for water/oil droplet and bubble on coking coal surfaces with different roughness," International Journal of Mining Science and Technology, vol. 31, no. 4, pp. 681-687, 2021.

[17] Y. Abbaspour-Gilandeh, F. Hasankhani-Ghavam, G. Shahgoli, V. R. Shrabian, and M. Abbaspour-Gilandeh, "Investigation of the effect of soil moisture content, contact surface material and soil texture on soil friction and soil adhesion coefficients," Acta Technologica Agriculturae, vol. 21, no. 2, pp. 44-50, 2018.

[18] S. Manuwa, "Evaluation of soil/material interface friction and adhesion of Akure sandy clay loam soils in southwestern Nigeria," Advances in Natural Science, vol. 5, no. 1, pp. 41-46, 2012.

[19] Y. Zhang, J. Qiu, Y. Zhang, and Y. Xie, "The adoption of a support vector machine optimized by GWO to the prediction of soil liquefaction," Environmental Earth Sciences, vol. 80, no. 9, pp. 1-9, 2021.

[20] Y.-g. Zhang, J. Qiu, Y. Zhang, and Y. Wei, “The adoption of ELM to the prediction of soil liquefaction based on CPT," Natural Hazards, vol. 107, no. 1, pp. 539-549, 2021.

[21] Y. Zhang, Y. Xie, Y. Zhang, J. Qiu, and S. Wu, "The adoption of deep neural network (DNN) to the prediction of soil liquefaction based on shear wave velocity," Bulletin of Engineering Geology and the Environment, vol. 80, no. 6, pp. 5053-5060, 2021.

[22] F. S. Khan and S. Azam, "Determination of the desiccation behavior of clay slurries," International Journal of Mining Science and Technology, vol. 27, no. 6, pp. 981-988, 2017.

[23] T. Qiu, C. Liu, X. Zhong, and Y. Zhu, "Experimental research on the impact of temperature on the adhesion characteristics 
of soil-structure interface," Geofluids, vol. 2020, Article ID 6675576, 9 pages, 2020.

[24] P. Soni and V. M. Salokhe, "Influence of dimensions of UHMW-PE protuberances on sliding resistance and normal adhesion of Bangkok clay soil to biomimetic plates," Journal of Bionic Engineering, vol. 3, no. 2, pp. 63-71, 2006.

[25] A. Khabbazi Basmenj, A. Mirjavan, M. Ghafoori, and A. Cheshomi, "Assessment of the adhesion potential of kaolinite and montmorillonite using a pull-out test device," Bulletin of Engineering Geology and the Environment, vol. 76, no. 4, pp. 1507-1519, 2017.

[26] M. Seeman, G. Ganesan, R. Karthikeyan, and A. Velayudham, "Study on tool wear and surface roughness in machining of particulate aluminum metal matrix composite-response surface methodology approach," The International Journal of Advanced Manufacturing Technology, vol. 48, no. 5-8, pp. 613-624, 2010.

[27] S. Adamczak, E. Miko, and F. Čuš, "A model of surface roughness constitution in the metal cutting process applying tools with defined stereometry," Strojniki Vestnik, vol. 55, no. 1, pp. 45-54, 2009.

[28] S. Kumar, R. Talreja, and V. M. S. R. Murthy, "Development of a drill energy utilization index for aiding selection of drill machines in surface mines," International Journal of Mining Science and Technology, vol. 27, no. 3, pp. 393-399, 2017.

[29] R. Deng, Study on the Mechanism and Disposal Measures of Clay Clogging in TBM Cutter-Head, Southwest Jiaotong University, 2018.

[30] C.-L. Qiu, Q.-J. Zhang, S.-W. Yan, and Y.-C. Ji, "Experimental study of adhesion of clay," Rock and Soil Mechanics, vol. 38, no. 5, pp. 1267-1272, 2017.

[31] M. Islam, L. Tong, and P. Falzon, "Influence of metal surface preparation on its surface profile, contact angle, surface energy and adhesion with glass fibre prepreg," International Journal of Adhesion and Adhesives, vol. 51, pp. 32-41, 2014.

[32] Y. Yuan and T. R. Lee, "Contact angle and wetting properties," in Surface Science Techniques, G. Bracco and B. Holst, Eds., Springer Berlin Heidelberg, Berlin, Heidelberg, 2013. 